\title{
Impact Internal Control on Efficiency of the Organizations in Jaffna District
}

\author{
Piriya Muraleetharan \\ Senior Lecturer, Faculty of Management Studies and Commerce \\ University of Jaffna, Sri Lanka \\ E-mail: piriyamuraleetharan@yahoo.co.in
}

Received: January 29, 2019 Accepted: December 3, 2019 Published: December 6, 2019

doi:10.5296/ijafr.v9i4.15992

URL: https://doi.org/10.5296/ijafr.v9i4. 15992

\begin{abstract}
This study was undertaken with the objective of finding Impact of Internal control on efficiency of organizations in Jaffna District. The study is based on twenty five organizations and wo hundred and forty four respondent in Jaffna District, which are private and public organizations in the district. Internal control assessment is measured by control environment, risk assessment; information and communication, control activities, and monitoring and financial performance is measured by efficiency. Internal control and efficiency measured by correlation analysis and regression analysis. The study finds internal control and efficiency are statistically significant in determining efficiency. Further the study suggests that work performed by the organizations have been implemented in the past and the work schedules take into consideration the goals of internal control. The study further points out that keen attention should be paid on to adopt efficient management information system and training of the staff. All these enhance the staff productivity and reducing costs and also ensure the efficient operation of the firms and financial performance of their operation as well.
\end{abstract}

Keywords: Efficiency, Internal control, Risk assessment and monitoring

\section{Background of the Study}

Every organization achieved their target in future years. Therefore Internal control is important task in every management process. It is a big issue in every organization regarding their control work. So internal control is a constituent of efficient company management. Every investors observe in every organization regarding their investment. Therefore the companies achieved their target, it target depends on internal process activities and efficiency of companies 
performance. In the competitive business environment, major objective of all organization is to achieve higher profitability or maximize its financial performance /Wealth. The effective executions of financial procedures heavily depend on internal control system.

The Board of Directors is thus responsible for providing governance, guidance and oversight for senior management and ensuring that an appropriate internal control system is in place and effective, meaning it ensures that expected objectives are attained.

Understanding the concept of internal control is essential for developing an understanding of its impact on the performance of an organization. The internal control system of an entity is strictly interrelated to the structure used by management to oversee the activities of the organization.

Efficiency is the ability to avoid wasting materials, energy, efforts, money, and time in doing something or in producing a desired result. In a more general sense, it is the ability to do things well, successfully, and without waste.

\subsection{Research Problem}

Internal control essential for in every organization, because the task of internal control main objective is to prevent and detect fraud in the organization. It is a function provided either by employees of the entity of sourced from an external organization to assist management in achieving corporate objectives.

The corporate governance procedures highlight the need for business to maintain good management system of internal control, to manage the risk the organizations faces. Internal audit can play a key role in assessing and monitoring internal control policies and procedures. Therefore internal control is needed to target efficiency and effectiveness of operations in meeting business objectives the preparation of reliable published financial accounts and the compliance with applicable laws and regulations. Even though the organizations operate its activities in order to achieve the benefit for its revenue generations and it can be attained through the internal control. Which have different components of control such as control activities, information and communication, control environment, risk assessment, and monitoring (COSO1994).

Identify the different in internal control mechanisms have the impact on monitoring quality and performance. That's why the present study is initiated to find out that to what extent of internal control on efficiency of public and private organizations in Jaffna district.

The following question is formed based on the discussion of literature study and research gap. Is there any impact of internal control on efficiency?

\section{Review of Literature}

Control is an emphasis on controls categorized as the control environment; management's philosophy and operating style, integrity and ethical values, assignment of authority and responsibility (e.g., accountability), human resource practices (e.g., training, performance appraisal, remuneration and compensation, employee counselling), audit committee, and internal audit. While long recognized as important (Haskins, 1987, Basu and Wright 1997) the considerable emphasis on the control environment is apparent in COSO "It is the basic components of all other variables, providing discipline and structure." Cohen, Krishnamoorthy 
and Wright (2000) explained that the importance of the environment with their finding from a survey of auditors that "tone at the top", and its implication for the behaviors of employees, is the most important ingredient for effective control.

Monitoring includes management's methods for following-up and checking on performance to ensure that controls are complied with monitoring component of the internal control system has made a circle and monitoring activities to help to improve control activities, information systems as well as overall internal control.

The importance of informal controls is well recognized in the management accounting (Langfield -Smith, 1995, Otley 1994) and is reflected in a small number of related studies in the audit area (Haskins 1987, Hooks et. al. 1994, Basu and Wright 1997).

Hooks et al. (1994) described the control environment "as in part, an operationalization of organizational culture". Schein (1989) defines organizational culture as, "the deeper level of basic assumptions and beliefs that are shared by members of an organization that operate unconsciously, and view of it and its environment. Collins and Porras (1994) described how culture might influence control in an organization embracing empowerment, "people who internalize a strong set of beliefs don't need command from above to be able both to 'do their own thing' and 'do the right thing' for the organization".

Ezzamel, Lilley and Willmott (1997) found control globalized into organizational issue in the form of self-discipline, has diminished the relevance of control. Placing greater authority and responsibility in the hands of fewer employees can therefore be reconciled with control by placing greater emphasis on the control environment.

Rittenberg et al. (2005) said that the control environment starts with the board of directors and management. It is affects organization through policies, behaviours and effective governance. If the management is identify, then fraudulent financial reporting is more likely to occur.

\subsection{Objectives}

- To examine the relationship between internal control and efficiency.

- To identify the major determinants of internal control.

- To understand the organization to increase the efficiency of the internal control.

\section{Methodology}

\subsection{Data Collection and Sampling Design}

Primary and secondary data are used for the study, Primary data has been collected through the questionnaire developed by the researcher after the review of literature and secondary data were collected from the books, journals etc.

In this study control environment, risk assessment, accounting and communication, control activities and monitoring are independent variables and efficiency is dependent variable is used in this study. The samples for the study were the public and private organizations in Jaffna district in Sri Lanka. An attempt, among 25 organizations and selected for 244 respondents 


\section{Mll Macrothink}

International Journal of Accounting and Financial Reporting

ISSN 2162-3082

2019, Vol. 9, No. 4

covering executive levels and related to the accounting level of types of employees were considered for the survey as an ultimate sample in the research.

\subsection{Research Hypotheses}

These based on the objectives above will be used to develop the testable hypothesis for the study.

$\mathrm{H}_{1}$ : There is a significant impact of internal control on efficiency of the organizations in Jaffna district.

$\mathrm{H}_{2}$ : There is a significant relationship between internal control and efficiency of the organizations in Jaffna district.

For this purpose some of the statistical analysis techniques are used in this research. Mainly in this research correlation and regression analysis were also used to test the hypothesis and significance using SPSS version 13.

\section{Analysis of the Result}

\subsection{Number of Respondents by Personal Characteristics}

The demographical variables of respondent's such as departments and position were analyzed and tabulated in the following tables. The following table illustrates the no of department respondents in organizations.

Table 1. No of respondents by departments

\begin{tabular}{lll}
\hline Departments & No of Respondents & Percentage \\
\hline Personal & 45 & $18.4 \%$ \\
\hline Finance & 143 & $58.6 \%$ \\
\hline Production & 22 & $9.0 \%$ \\
\hline Sales \& marketing & 20 & $8.2 \%$ \\
\hline Any Other & 14 & $5.7 \%$ \\
\hline Total & 244 & $100.0 \%$ \\
\hline
\end{tabular}

The above table indicates the respondents of departments. Most of the departments constituting $58.6 \%$ were in the Finance departments and $18.4 \%$ and $9.0 \%$ of the departments were at the personal and production departments are respectively.

Table 2. No of respondents by positions

\begin{tabular}{lll}
\hline Positions & No of Respondents & Percentage \\
\hline Low level & 56 & $23.0 \%$ \\
\hline
\end{tabular}




\begin{tabular}{lcc}
\hline Middle level & 141 & $57.8 \%$ \\
\hline Higher level & 47 & $19.2 \%$ \\
\hline Total & 244 & $100.0 \%$
\end{tabular}

Table 2 indicates the level of respondents. Most of the respondents constituting $57.8 \%$ were in the middle level.23\% and $19.3 \%$ of the respondents were at the lower level and higher level respectively.

\subsection{Reliability Analysis}

Reliability test was used to test the reliability of the variables with the sample of 30.This purpose the Cronbach's alpha value was computed and checked. The result of Cronbach's alpha of internal control and efficiency are 0.823 and 0.84 respectively. According to this result, it shows that the questions issued to the respondent, are more reliable for this measurement of effective internal control and efficiency of the organizations.

Reliability analysis on item scale was performed using SPSS. Cronbach's alpha as suggested by many experts (Page \& Meyer .2000) for each variable with item-scales. Results have been presented below.

Table 3. Scale reliability independent variables

\begin{tabular}{ll} 
Concept/Independent Variables & Cronbach's alpha \\
\hline Control Environment & .74 \\
\hline Risk Assessment & .82 \\
\hline Control Activities & .85 \\
\hline Accounting. Information & .81 \\
\hline Monitoring & .83 \\
\hline
\end{tabular}

As further Table 3 Cronbach's alpha value for each components of internal control is more than 0.7 which is highly reliable and then an attempt was made to compute Cronbach's alpha value for component of efficiency. This result is tabulated in Table 4.

Table 4. Scale reliability Dependent variables

Concept/Dependent Variables Cronbach's alpha

$\begin{array}{ll}\text { Efficiency } & .83\end{array}$




\section{Macrothink}

International Journal of Accounting and Financial Reporting

ISSN 2162-3082

2019, Vol. 9, No. 4

As further Table 4 Cronbach's alpha value for each components of efficiency is more than 0.7 which is highly reliable. Hence the researcher decided to continue the study.

\subsection{Validity}

Researcher identified the variables which are related to internal control through the extensive literature survey control environment, risk assessment, information and communication, control activities, and monitoring are the more suitable factors to measure the internal control. Because the researchers used these variables for the purpose of same study. (Faudziah Hanim, 2005). These are purely suited for our Sri Lankan context. Similarly efficiency is the most commonly used variable for the measurement

\subsection{Descriptive Statistics - Internal Control}

Descriptive statistics were used to identify the importance of the factors such is control environment, risk assessment, control activities, accounting information and communication and monitoring. In order to rank them, the ranking of the factors were made on the basis of mean and std. deviation. The Table 5 presents these details.

Table 5. Descriptive statistics for internal Control

\begin{tabular}{lllll}
\hline Independent Variable & Mean & Rank (Mean) & Std. Deviation & Rank (Std. Deviation) \\
\hline Control Environment & 12.46 & 1 & 3.19 & 2 \\
\hline Risk Assessment & 12.10 & 5 & 3.24 & 4 \\
\hline Control Activities & 12.27 & 4 & 3.15 & 1 \\
\hline $\begin{array}{l}\text { Accounting } \\
\text { Information }\end{array}$ & 12.39 & 2 & 3.56 & 5 \\
\hline Monitoring & 12.34 & 3 & 3.23 & 3 \\
\hline
\end{tabular}

Table 5 shows the means and std. deviation of the components of the internal control system. From the results, the control environment component of internal control system is a highly rated item with a mean value of 12.46 while risk assessment is the least rated item with a mean value of 12.10.The control activities component of internal control system is a highly rated item with std. deviation value of 3.15 while accounting and information is the least rated item with std. deviation value of 3.56 .

This section deals with the detailed analysis of impact of effective internal control and financial performance.

Whole analysis carried out by using various statistical tools. Multiple regression analysis, ANOVA test, and correlation analysis carried out to find the decision between internal control and efficiency of the organization. 


\subsection{The Relationship Between Internal Control and Efficiency}

The aim of the present study is to identify the relationship between internal control and efficiency. For this purpose the correlation analysis were used and the results are presented by the table.

Table 6. Correlation Internal control and efficiency

\begin{tabular}{lll}
\hline & & Efficiency \\
\hline Internal Control & Pearson Correlation & $.891(* *)$ \\
\hline Sig. (2-tailed) & .000 \\
\hline $\mathrm{N}$ & 244 \\
\hline
\end{tabular}

** Correlation is significant at the 0.01 level (2-tailed)

The table shows the relationship between internal control and efficiency. Accordingly the correlation value is 0.891 which $\mathrm{b}$ is significant at 0.01 levels. It means when the internal control increases the efficiency increases.

To test the hypothesis, correlation analysis was used and value of $0.891(\mathrm{p}<0.01)$ indicate that internal control system and efficiency is positively correlated. Hence the hypothesis is accepted.

In this analysis we tried to find out the impact of internal control system on efficiency for this purpose multiple regression analysis was used and the results are tabulated by Table 6 .

Table 7. Predictors of efficiency

\begin{tabular}{lllll}
\hline Variables & $\begin{array}{l}\text { Un } \\
\text { standardized } \\
\text { Coefficient } \\
\mathrm{b}\end{array}$ & $\begin{array}{l}\text { Standardized } \\
\text { Coefficient }-\beta\end{array}$ & $\mathrm{t}$ - value & $\begin{array}{l}\mathrm{P} \text {-value } \\
\text { Significance }\end{array}$ \\
\hline Constant & 1.784 & & 3.672 & .000 \\
\hline Control environment & -.051 & -.052 & -.900 & .369 \\
\hline Risk assessment & .278 & .293 & 4.487 & .000 \\
\hline Control Activities & .187 & .193 & 3.003 & .003 \\
\hline Information and communication & .254 & .286 & 4.540 & .000 \\
\hline Monitoring & .193 & .203 & 3.326 & .001 \\
\hline $\mathrm{R}^{2}: .698$ & & Adj $\mathrm{R}^{2}: .691$ & & F: 109.792 \\
\hline
\end{tabular}




\section{MlMacrothink}

International Journal of Accounting and Financial Reporting

ISSN 2162-3082

The specification of the internal control variables in the above model denotes that the $\mathrm{R}^{2}$ value of 0.698 which indicates that $69.8 \%$ of a variation in the dependent variable is observed. Further examination of $t$ values indicates that the all variables are statistically significant. The table indicates that coefficients for the all variables are in the expected direction with the exception of variable control environment. Thus hypothesis is accepted.

\section{Conclusion}

The study was carried out to find out the impact of effective internal control on efficiency of organizations of Jaffna District. Further this study is mainly tested by using correlation and regression analysis. Through this present study's hypotheses are tested. As expected risk assessment, control activities, accounting and communication and monitoring are statistically significant determinants of efficiency of the organizations. Other variable which is considered to the analysis, control environment though not statistically significant but expressed the expected way of relationship with the dependent variable, i.e., efficiency.

The important of risk assessment, control activities, accounting and communication and monitoring of the internal control lead to better efficiency. In performing the control environment, the internal control will identify better management framework, policy and also better procedures should be installed in efficiency of policies and procedures of the organizations. The better the control environment, the installation of the procedures and application of policies in assessing the risk of the organization will further improve.

The institutions should adopt efficient management information system. Organizations, even the smallest, have reached a level of operation that requires adequate management information system. Using management information software as well as other innovative technologies can contribute to a reduction in administrative costs, an increase in staff productivity and improvement in the reality of accounts. While using new technology can be strongly beneficial for organizations, it is equally true that it introduces additional costs to the institutions. Thus it is the organizations' responsibility to identify the best practices as well as cost - effective ways to use new technology to improve outreach, efficiency, and satisfaction, which are becoming requirements of Efficiency in organization.

\section{References}

Basu, P., \& Wright, A. (1997). An Exploratory Study of Control Environment Risk Factors: Client Contingency Considerations and Audit Test Strategy. International Journal of Auditing, 1(2).

Cohen, J., Krishnamoorthy, G., \& Wright, A. (2000, January). Corporate Governance and the Audit Process. Midyear Auditing Conference. LA.

COSO. (2011). Enterprise risk management integrated framework. Committee of Sponsoring Organizations of the Treadway Commission.

Ezzamel, M., Lilley, S., \& Willmott, H. (1997). Accounting for Management and Managing Accounting: Reflections on Recent Changes in the UK. Journal of Management Studies, 34. 


\section{NI Macrothink}

International Journal of Accounting and Financial Reporting

ISSN 2162-3082 2019, Vol. 9, No. 4

Fadzil, F. H., Haron, H., \& Jantan, M. (2005). Internal auditing practices and internal control system in Malaysian listed company. Managerial Auditing Journal, 20(8), 844-866.

Haskins, M. (1987). Client Control Environments: An Examination of Auditors Perceptions. The Accounting Review.

Hooks, K. L., Kaplan, S. E., \& Schultz, J. J. (1994). Enhancing Communication to Assist in Fraud 47 Prevention and Detection. Auditing: A Journal of Practice and Theory, 13, 86-117.

Hooks, K. L., Kaplan, S. E., \& Schultz, J. J. Jr. (1994). Enhancing Communication to Assist in Fraud Prevention and Detection. Auditing: A Journal of Practice and Theory, 13.

Langfield-Smith, K. (1995). Organizational culture and control. In A.J. Berry, J. Broadbent, \& D. Otley (Eds.), Management Control, Theories, Issues and Practices. MacMillan Press, London.

Page, C., \& Meyer, D. (2000). Applied Research Design for Business and Management. The McGraw-Hill Companies, Ins.

Rittenberg, L. E., \& Schwieger, B. J. (2005). Auditing - Concepts for a Changing Environment. Mason: South-Western, Thomson Corporation.

\section{Copyright Disclaimer}

Copyright for this article is retained by the author(s), with first publication rights granted to the journal.

This is an open-access article distributed under the terms and conditions of the Creative Commons Attribution license (http://creativecommons.org/licenses/by/4.0/) 